\title{
Experimental autoimmune uveoretinitis in the RCS rat: the influence of photoreceptor degeneration on disease expression
}

\author{
E G Atkinson, C Edelsten, Eva Kasp, D C Dumonde
}

\begin{abstract}
S-antigen induced experimental autoimmune uveoretinitis (EAU) was produced in the Royal College of Surgeons (RCS) strain of rat which develops a photoreceptor dystrophy within 2 weeks of birth. Animals were sensitised at 60, 90, and 105 days of age: all animals developed disease, but onset was significantly delayed in older (105 day) animals compared with those aged 60 days at sensitisation (p 0.003). Disease was characterised by the early development of complete serous retinal detachment which resolved in a few days: the prevalence of retinal detachment was increased to $80 \%$ in dystrophic animals compared with $10 \%$ in the congenic, non-dystrophic controls $(p<0.001)$. Anterior uveitis was seen in 17/30 control strain eyes, but in none of 30 dystrophic eyes $(p<0.001)$. Genetically determined photoreceptor and retinal pigment epithelium dysfunction in the RCS rat, which may involve the local accumulation of altered S-antigen, predisposes the dystrophic strain to display an acute retinal detachment in the early stages of EAU. This phenomenon illustrates how biochemical dysfunction of a target organ may influence susceptibility, form, and severity of an experimental autoimmune disease.

(Brf Ophthalmol 1992; 76: 553-559)
\end{abstract}

Experimental autoimmune uveoretinitis (EAU) is a model of human uveoretinal inflammation, produced by sensitisation of susceptible animal species to discrete retinal proteins, and results in photoreceptor necrosis. Retinal S-antigen, which is confined to the photoreceptors and pineal gland, was the first purified protein demonstrated to produce EAU, and has been the most intensively studied.' Autosensitisation to retinal proteins is considered possible because of their anatomical sequestration from the developing immune system. When immunocompetent animals are then sensitised to $S$ antigen, $T$ helper cells and, later, $T$ cytotoxic/ suppressor cells enter the photoreceptor layer and are presumed to produce the characteristic damage. ${ }^{2}$ Disruption of the blood-retinal barrier and destruction of photoreceptors promote further access to and recognition of the target antigens by the sensitised immune system. On this basis, continued interaction between the immune system and components of the photoreceptor layer depends on the continuing availability of photoreceptor antigens to the sensitised immune system. Indeed, when the normal turnover of S-antigen at the photoreceptor outer segments is disrupted, as is seen after retinal light damage or dark adaptation, the severity and chronicity of $\mathrm{S}$-antigen induced uveoretinitis is reduced. ${ }^{3}$

Against this background it seemed likely that susceptibility to and severity of EAU could well be affected by coexisting photoreceptor pathology. The Royal College of Surgeons (RCS) strain of rat develops an inherited photoreceptor dystrophy: its abnormal retinal pigment epithelium is unable to phagocytose effectively the photoreceptor outer segment membranes. The photoreceptors start to degenerate within 2 weeks of birth, and cellular debris accumulates spontaneously in the subretinal space: by 2 months of age, the outer nuclear layer is reduced to a thickness of two nuclei. The subretinal debris begins to disappear by 3 months of age, but some may persist for up to 18 months. Eventually, the inner nuclear layer rests on the pigment epithelium, the retinal pigment epithelium (RPE) becomes vascularised and there is gliosis within the remaining retina..$^{48}$ The black-eyed strain of RCS rat has a pigmented fundus that allows funduscopic and angiographic assessment to be combined. ' We considered that a comparative study of EAU in congenic, non-dystrophic rats of the same strain would enable evaluation of the influence of photoreceptor dystrophy on disease expression. Accordingly we have studied the form and severity of EAU in RCS dystrophic rats, sensitised at different ages, using congenic, nondystrophic pigmented rats as controls, and characterising the uveoretinitis by funduscopic, angiographic, and histopathological criteria.

\section{Materials and methods}

Fifteen dystrophic and 15 control strain RCS rats were sensitised with $50 \mu \mathrm{g}$ of retinal S-antigen in adjuvant so as to induce EAU. They were examined initially at 2-3 day intervals from 14 45 days after sensitisation, and then followed-up until day 81: fundus photography and fluorescein angiography were used to document changes in the clinical signs. The animals were then killed on day 86 post sensitisation, and the eyes removed for histological examination. Initial experiments ${ }^{10}$ had suggested that the time of onset of disease in dystrophic rats depended on age at sensitisation, and that no such relationship was found in the control strain. Accordingly in this study the dystrophic animals were sensitised at three different ages: 60 days (five rats), 85-90 days (seven rats) and 105 days (three rats). Nondystrophic controls were sensitised at 60 days (four rats) and 85-90 days (11 rats).

Experiments consisted of documenting the

United Medical and
Dental Schools of Guy's
and St Thomas'
Hospitals, St Thomas'
Campus, London
Department of Medical
Ophthalmology
E G Atkinson
C Edelsten
Department of
Immunology
E G Atkinson
C Edelsten
E Kasp
D C Dumonde
Correspondence to:
Dr C Edelsten, Department of
Immunology, The Rayne
Institute, St Thomas'
Hospital, London SE1 7EH.
Accepted for publication
28 February 1992


ophthalmoscopic and histopathological features of uveoretinitis in dystrophic and control strains at early, intermediate, and late stages of disease; and of examining relationships between the age of onset of EAU and age of rats at sensitisation. Strain differences in the prevalence of EAU or of retinal detachment were evaluated by $\chi^{2}$ analysis and relationships between time of onset of EAU and age of rats at sensitisation were examined by the Wilcoxon rank sum test.

INDUCTION OF EAU IN RCS RATS

RCS, black-eyed dystrophic rats ( $\left.r d y / r d y ~ p^{+}\right)$ were obtained from the Central London Polytechnic breeding colony, together with 15 control strain rats $\left(\mathrm{rdy}^{+} / \mathrm{p}^{+}\right)$. They weighed $100-150 \mathrm{~g}$ and were maintained under nonspecific pathogen free conditions. Animals were sensitised in the hind foot pads with $50 \mu \mathrm{g}$ of Santigen in Freund's complete adjuvant (FCA: Sigma) in an injection volume of $100 \mu l$. Bovine S-antigen, prepared by previously published methods, ${ }^{11}$ was dissolved in phosphate buffered saline (PBS) to $0.5 \mathrm{mg} / \mathrm{ml}$ and emulsified with an equal volume of FCA fortified with heat-killed Mycobacterium tuberculosis (3 mg/ml: MAFF, Weybridge, England). Simultaneously, $10^{6}$ heat inactivated Bacillus pertussis organisms were given intraperitoneally in $0.25 \mathrm{ml}$ PBS.

CLINICAL AND ANGIOGRAPHIC ASSESSMENT OF EAU Animals were examined by slit-lamp and indirect ophthalmoscopy, after mydriasis with $1 \%$ tropicamide (Smith and Nephew). The presence of the following clinical features were recorded separately on each occasion: anterior uveitis, retinal detachment, disc oedema, retinal venous dilatation and periphlebitis, retinal infiltrates, and abnormalities of the retinal pigment epithelium. Selected features were recorded by fundus photography. Fluorescein angiography was performed under Thalamonal anaesthesia, $0.05 \mathrm{ml} / \mathrm{kg}$ (Janssen, Oxford). Sodium fluorescein $(4 \% ; 0.1 \mathrm{ml})$ was injected via the tail vein. Angiograms were recorded using a Zeiss fundus camera using Ilford FP4 film.

HISTOLOGICAL PROCESSING

At termination of the experiment, animals were

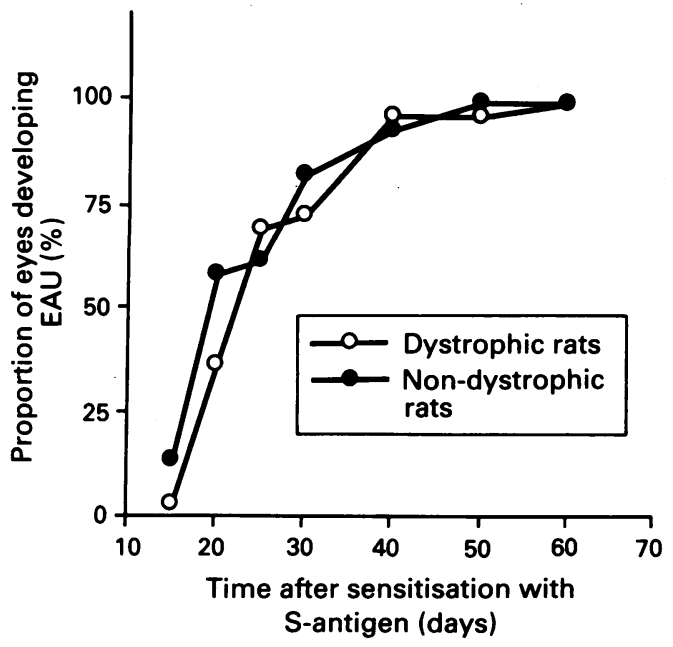

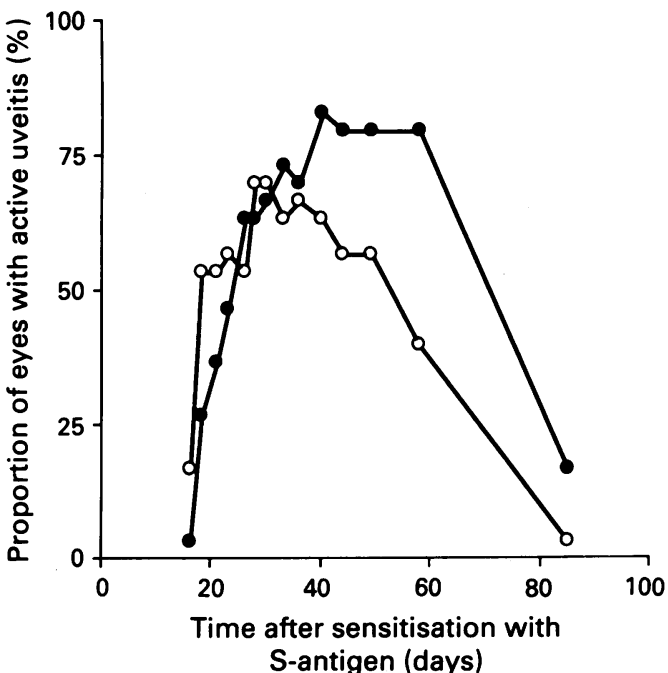

Figure 2 Prevalence of active uveitis in RCS dystrophic rats and non-dystrophic controls compared with time after sensitisation. $(\mathrm{O})=$ dystrophic, $(\mathrm{O})=$ non-dystrophic.

killed by cardiac puncture under ether anaesthesia. Eyes were removed, fixed in $4 \%$ glutaraldehyde (EM grade, Emscope Laboratories) for 12 hours, then $10 \%$ formaldehydesaline $(\mathrm{BDH})$; followed by vacuum wax embedding and haematoxylin and eosin staining.

\section{Results}

PREVALENCE AND COURSE OF CLINICAL DISEASE IN RCS RATS

All animals developed EAU (Fig 1). The dystrophic strain tended to develop disease earlier, and resolve quicker. At day 18 there were significantly more dystrophic rats with disease than controls $\left(16 / 30\right.$ eyes vs $8 / 30$ eyes: $\chi^{2}=4 \cdot 44$, $\mathrm{p}<0.05$ ). but by day 58 there were significantly fewer dystrophic animals with disease compared with controls $(12 / 30$ vs $24 / 30, \mathrm{p}<0.01)$ (Fig 2$)$. However, there was no significant difference in the time of disease onset between the dystrophic rats [median 18 days (range 15-46)], and controls [23.5 days (15-55)], or the length of active disease between the two groups: 24 days (3-51) in dystrophic strain vs 29 days $(8-61)$ in control strain. Four non-immunised control strain rats and three non-immunised dystrophic rats did not develop uveitis.

When the animals were grouped according to age at immunisation (Table 1), a tendency for disease onset to be delayed with increasing age at immunisation in the dystrophic rats was found. Animals sensitised at 60 days of age developed

Table 1 Relationship between time of onset of EAU and age of RCS rats at sensitisation with $S$-antigen

Figure 1 Cumulative onset of $E A U$ in black-eyed RCS dystrophic and nondystrophic rats. The figure displays the relationship between the proportion of affected eyes, and time after sensitisation with $50 \mu \mathrm{g}$ bovine $S$-antigen in $F C A$ together with $\mathrm{B}$ pertussis inoculation (see Methods).

\begin{tabular}{|c|c|c|}
\hline \multirow[b]{2}{*}{$\begin{array}{l}\text { Age at sensitisation } \\
\text { (days) }\end{array}$} & \multicolumn{2}{|c|}{ Onset of EAU (days after sensitisation) } \\
\hline & $\begin{array}{l}\text { Dystrophic strain } \\
\text { Mean }(S D)\end{array}$ & $\begin{array}{l}\text { Non-dystrophic strain } \\
\text { Mean }(S D)\end{array}$ \\
\hline $\begin{array}{l}60 \\
85-90 \\
105\end{array}$ & $\begin{array}{l}18 \cdot 9(5 \cdot 1)(n=9)^{\star} \\
22 \cdot 3(8 \cdot 4)(n=14) \\
30 \cdot 5(8 \cdot 3)(n=6)^{\star}\end{array}$ & $\begin{array}{l}26 \cdot 1(5 \cdot 0)(n=8) \\
26 \cdot 0(10 \cdot 5)(n=22) \\
\text { ND }\end{array}$ \\
\hline
\end{tabular}

$\star_{n}=$ no of eyes

Onset of EAU in dystrophic rats sensitised at 105 days was delayed in comparison with rats sensitised at 60 days $(p=0 \cdot 003$, Wilcoxon
rank sum test). 
Table 2 Clinical features of uveoretinitis in dystrophic and control strain RCS rats

\begin{tabular}{|c|c|c|c|c|c|c|}
\hline \multirow{3}{*}{$\begin{array}{l}\text { Prevalence of } \\
\text { clinical features (\%) }\end{array}$} & \multicolumn{6}{|c|}{ Stage of disease } \\
\hline & \multicolumn{2}{|c|}{$\begin{array}{l}0-5 \text { days } \\
\text { early }\end{array}$} & \multicolumn{2}{|c|}{$\begin{array}{l}\text { 10-15 days } \\
\text { intermediate }\end{array}$} & \multicolumn{2}{|c|}{$\begin{array}{l}25-30 \text { days } \\
\text { late }\end{array}$} \\
\hline & $D$ & $C$ & $D$ & $C$ & $D$ & $C$ \\
\hline $\begin{array}{l}\text { Retinal detachment } \\
\text { Anterior uveitis } \\
\text { Retinal vasculitis } \\
\text { Disc oedema } \\
\text { Pigmentary changes }\end{array}$ & $\begin{array}{r}52 \\
0 \\
37 \\
44 \\
0\end{array}$ & $\begin{array}{r}3 \\
26 \\
52 \\
38 \\
3\end{array}$ & $\begin{array}{r}0 \\
0 \\
42 \\
61 \\
27\end{array}$ & $\begin{array}{r}1 \\
12 \\
41 \\
68 \\
18\end{array}$ & $\begin{array}{r}0 \\
0 \\
33 \\
35 \\
93\end{array}$ & $\begin{array}{r}6 \\
0 \\
55 \\
71 \\
61\end{array}$ \\
\hline
\end{tabular}

$\mathrm{D}=$ dystrophic strain; $\mathrm{C}=$ control strains

Fifteen animals of each strain were examined on three different

days during the three time intervals. The prevalence of individua features of disease is expressed as a percentage of 90 observations at these three stages.

uveitis with a mean onset of 19 days, while those sensitised at 105 days of age developed disease at a mean time of 31 days $(p=0 \cdot 003$, Wilcoxon rank sum test). No such tendency was seen in the control animals. It was concluded that whereas both dystrophic and non-dystrophic rats were susceptible to disease, the dystrophic strain showed a delay in developing disease with increasing age at sensitisation.

CLINICAL FEATURES OF DISEASE IN DYSTROPHIC VS NON-DYSTROPHIC CONTROLS

All animals showed retinal inflammation by indirect ophthalmoscopy; patchy retinal infiltrates, venous dilatation, tortuosity, periphlebitis, and disc oedema. Disc oedema persisted for a few weeks after other signs of retinal vasculitis has subsided. The fundal view was not clouded by vitritis, but severe anterior uveitis prevented funduscopy for a few days in some animals. The fundal appearances were similar in the two strains and resembled the previously reported changes in the Lister rat. ${ }^{12}$

Abnormalities of retinal pigmentation, consisting of patchy hyperpigmentation and atrophy, developed in both dystrophic animals and non-dystrophic controls. There was no difference in the age of onset of pigmentary changes between animals of the two strains, whether

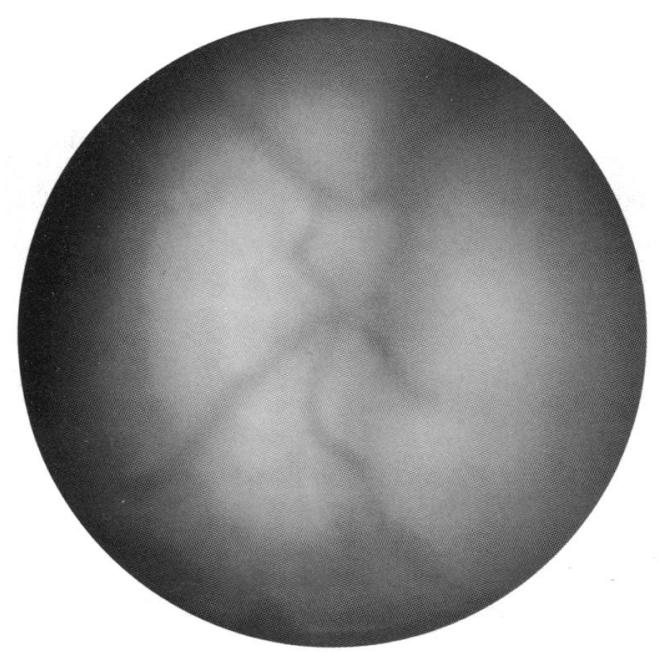

Fig $3 A$

Figure 3 Fundus photographs and fluoroscein angiograms of dystrophic rats showing clinical features of EAU. (A) serous retinal detachment; $(B)$ normal optic disc; $(C)$ swollen optic disc with dilated retinal vessels; $(D)$ peripheral retinal phlebitis; $(E)$ and $(F)$ are angiograms corresponding to the areas shown in $(C)$ and $(D)$, demonstrating dilated vessels and capillary and venous leakage. sensitised or not (mean age at onset 123 days, $95 \%$ confidence interval $117-129)$.

There was a striking difference in the initial phases of disease between dystrophic and nondystrophic controls (Table 2): 17/30 eyes of the control strain developed anterior uveitis with presentation of the uveitis. In contrast, anterior uveitis was not seen in any of the dystrophic animals $\left(\chi^{2}=23 \cdot 7, P<0 \cdot 001\right)$.

Early disease in the dystrophic strain were characterised by the sudden onset of serous retinal detachment which subsided after a few days; this was followed by other signs of retinal vasculitis similar to those seen in the control strain. Eighty per cent (24/30) of dystrophic eyes developed total serous retinal detachments in the first week of disease compared with $10 \%$ (3/30) of control strain eyes $\left(\chi^{2}=29 \cdot 7, p<0.001\right)$.

\section{FLUORESCEIN ANGIOGRAPHY AND HISTOLOGY}

Fluorescein angiograms showed leakage from the optic disc and areas of intraretinal infiltrates during active disease: no such leakage was seen prior to the development of clinical signs (Fig 3). There was no difference in the angiographic appearances between dystrophic and control strains, and appearances were again similar to those previously reported in the Lister rat. ${ }^{12}$ During the phase of serous retinal detachment there was widespread, diffuse leakage of fluorescein in the subretinal space.

Unsensitised dystrophic rats showed the reported changes of photoreceptor dystrophy with extensive loss of the photoreceptor cells and the spontaneous accumulation of debris in the subretinal space (Fig 4A).

All sensitised animals developed an extensive mononuclear infiltrate surrounding the retinal vessels, but minimal choroidal inflammation was seen. The optic disc region showed gross oedema and leucocytic infiltration. In non-dystrophic animals that had developed mild clinical disease, there were local retinal infiltrates but the surrounding retinal architecture remained normal

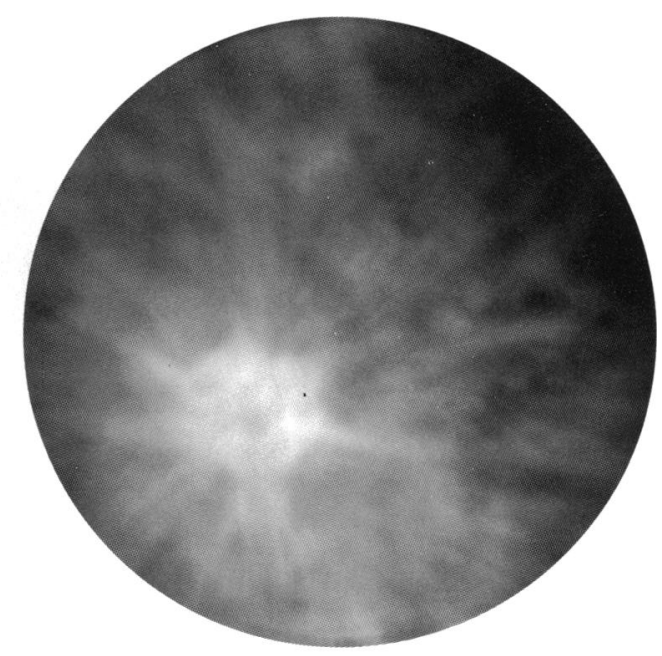

Fig $3 B$ miosis and synechiae formation as the initial 


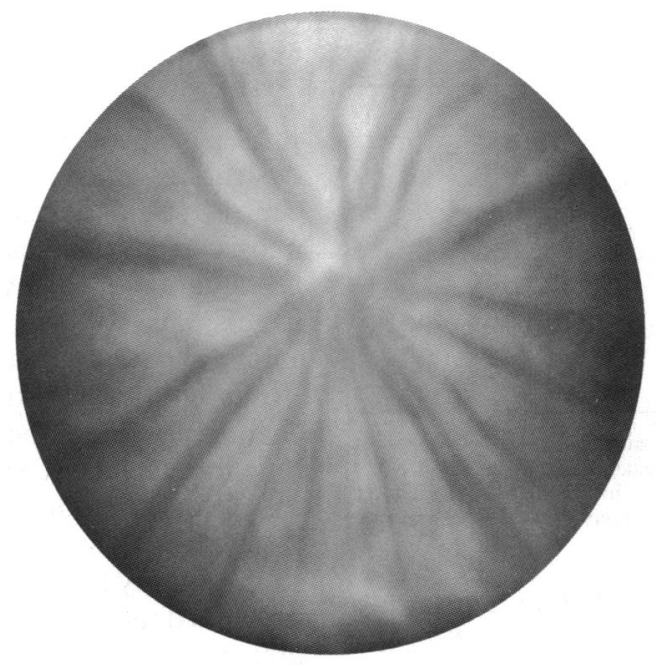

Fig 3C

(Fig 4B). In the dystrophic animals leucocytic infiltration into the retina was characteristically diffuse rather than focal and of greater severity than in the non-dystrophic strain. In the late stages of EAU dystrophic animals showed loss of subretinal debris with thinning of the neural retina; a small inflammatory infiltrate remaining in the inner retina at a time wher funduscopic evidence of disease was no longer evident (Fig 4C). In late EAU there were extensive areas of gliosis accompanied by neovascularisation in the dystrophic retina (Fig 4D). Although similar changes could be seen in the control strain, they were much less widespread than in the dystrophic strain. In the anterior segment there was mononuclear cell infiltration of the ciliary body and occasionally evidence of posterior synechiae. In an earlier series of experiments, ${ }^{10}$ animals were sacrificed during the early stages of disease. Figure 4E shows the detached retina of a dystrophic rat sensitised according to an identical protocol at the age of 60 days. The animal was sacrificed 14 days after sensitisation and 3 days after the onset of extensive serous detachments. Large clumps of granulocytes and mononuclear cells are seen in the subretinal space.

\section{Discussion}

In this study we have demonstrated that the RCS

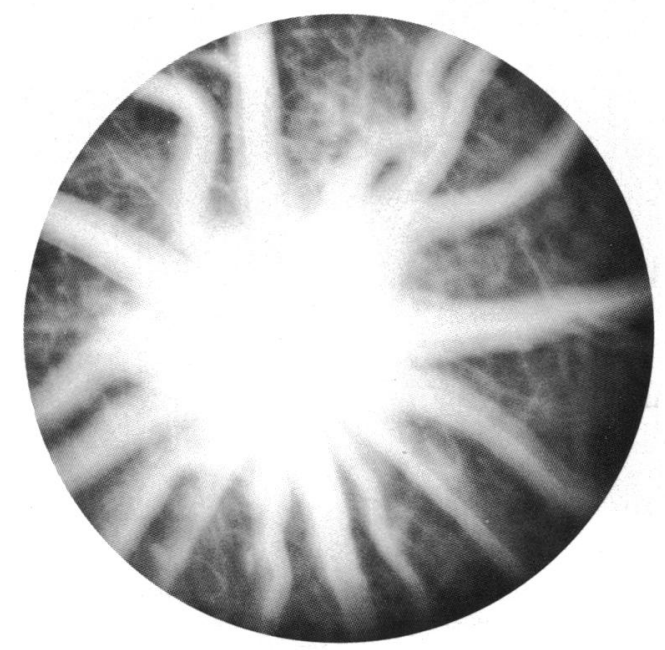

Fig $3 E$

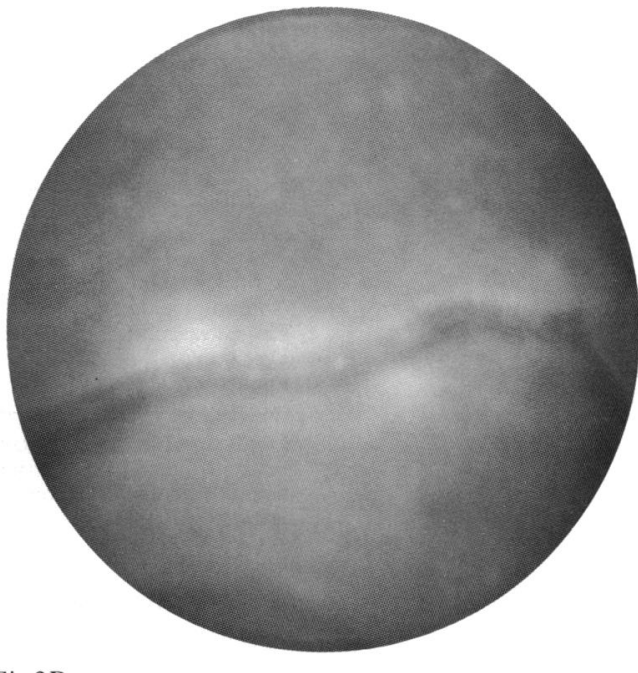

Fig 3D

rat is suceptible to EAU after sensitisation with retinal S-antigen, though older animals with photoreceptor dystrophy show a delay in disease onset. The presence of photoreceptor dystrophy was associated with a marked alteration in the form of early clinical disease from an acute anterior uveitis to that of a complete serous retinal detachment. As the two strains of rat differed only by the presence or absence of the photoreceptor dystrophy gene(s) we presume that these differences in disease expression were not due to differences in immune responsiveness or to differences in ocular vascular anatomy between the strains. In general the photoreceptor layer is the site of the most profound T lymphocyte infiltrate and retinal cell destruction in EAU, while in the Lewis rat initial $\mathrm{T}$ lymphocyte infiltration occurs in the ciliary body.$^{13}$ The route and severity of early cellular infiltration into the eye in EAU varies with the ocular vascular anatomy, the dose of antigen, the composition of adjuvant as well as between strains of the same species. ${ }^{14-18}$ In EAU, fluorescein angiography and electroretinography demonstrate that the cellular infiltrate is preceded by a period of increased retinal vascular permeability and abnormal photoreceptor function, and there is

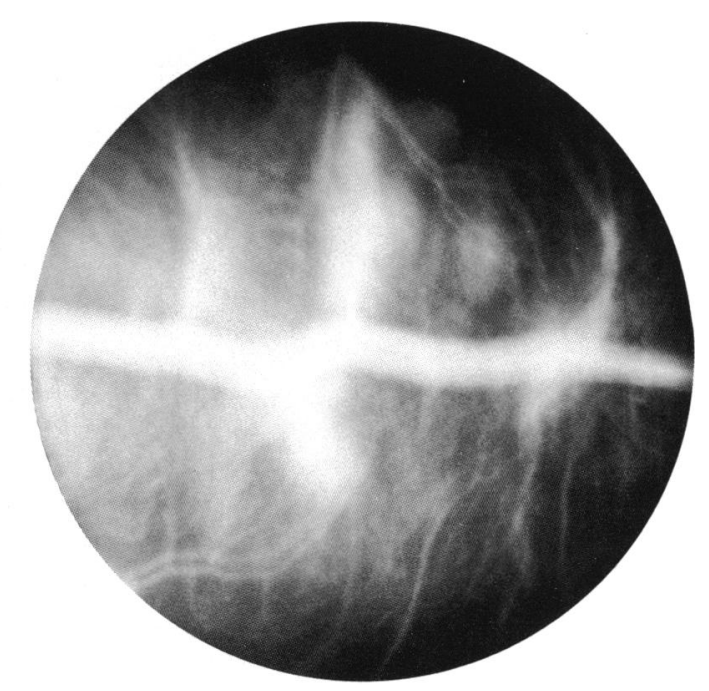

Fig $3 F$ 
Figure 4 Histology of

posterior segment changes in $E A U$ produced in dystrophic and non-dystrophic RCS rats (haematoxylin and eosin). (A) Section from nonsensitised dystrophic rat, 60 days old, showing extensive loss of photoreceptor cells and their replacement with amorphous debris $(\times 130)$. (B) Section from nondystrophic rat 86 days after sensitisation. There is a foca outer retinal infiltrate with adjacent disruption of the $R P E$. The surrounding retina shows normal photoreceptor layer morphology $(\times 150) .(C)$ Section from dystrophic rat with clinically inactive disease, 86 days after sensitisation. There is total loss of photoreceptor layer and associated debris. The inner retina is disrupted and there is irregularity of pigmentation at the $R P E$ $(\times 150)$. (D) Area of neovascularisation in dystrophic rat, 86 days after sensitisation $(\times 150)$. $(E)$ Section taken during the phase of acute retinal detachment, 14 days postsensitisation in a dystrophic rat. There is a marked serou elevation of the retina with subretinal aggregates of mononuclear cells and granulocytes. A mild infiltrate is present in the outer retina $(\times 66)$.

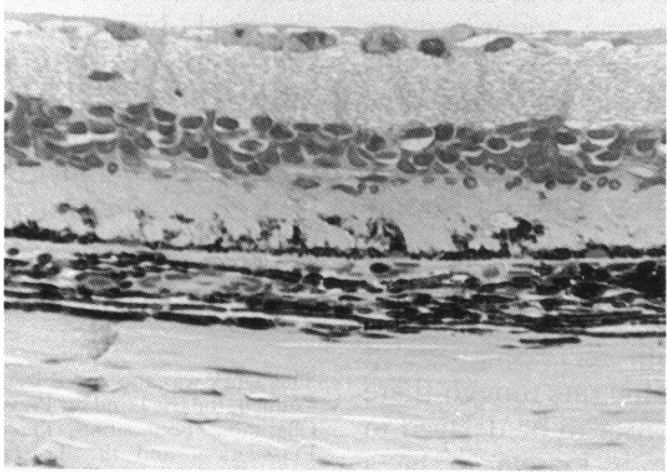

Fig $4 A$

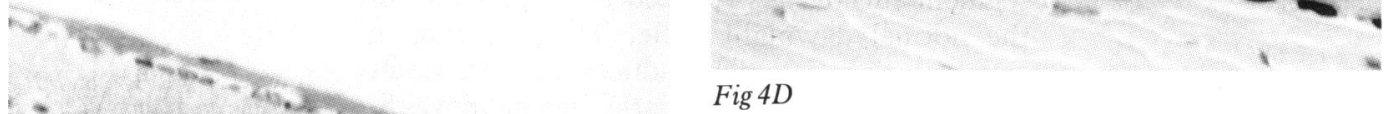

some evidence that humoral factors may be responsible for those early changes. ${ }^{12+19}$ Retinal detachment is known to occur during EAU in species other than the rat $^{16}$ where it is usually adjacent to areas of choroiditis and to RPE proliferation; and where the subretinal fluid contains lymphocytes and macrophages derived from the choriocapillaris. Extensive retinal detachment with subretinal granulocyte exudation can occur in hyperacute EAU in the Lewis rat, induced by high-dose sensitisation with S-antigen, where it is considered to be immune-complex mediated. ${ }^{16}$

The retina of the RCS rat has three characteristics which may predispose it to develop retinal detachment so readily in EAU. Firstly, normal adhesion of the retina to the pigment epithelium is compromised by the loss of interdigitations between the photoreceptors and RPE, as the outer segments degenerate and

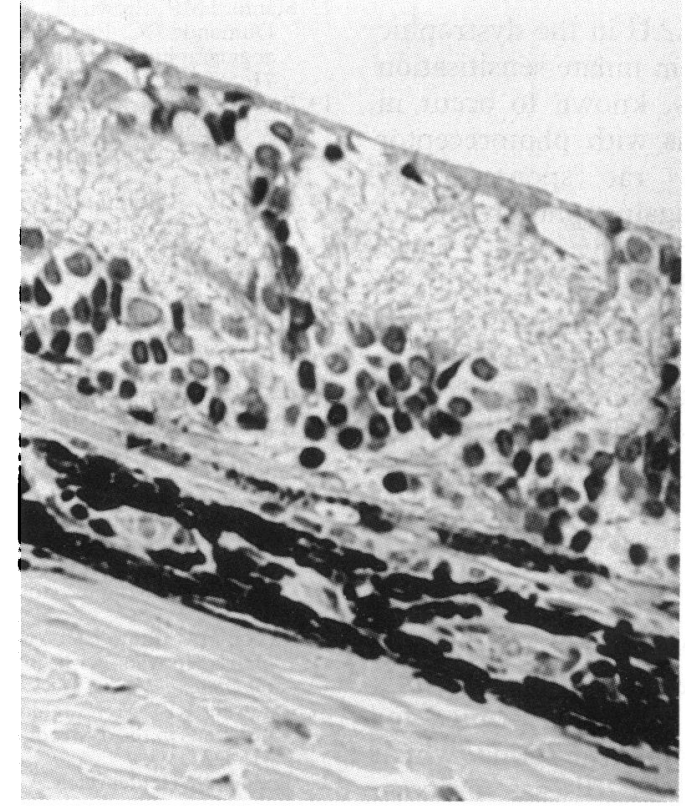

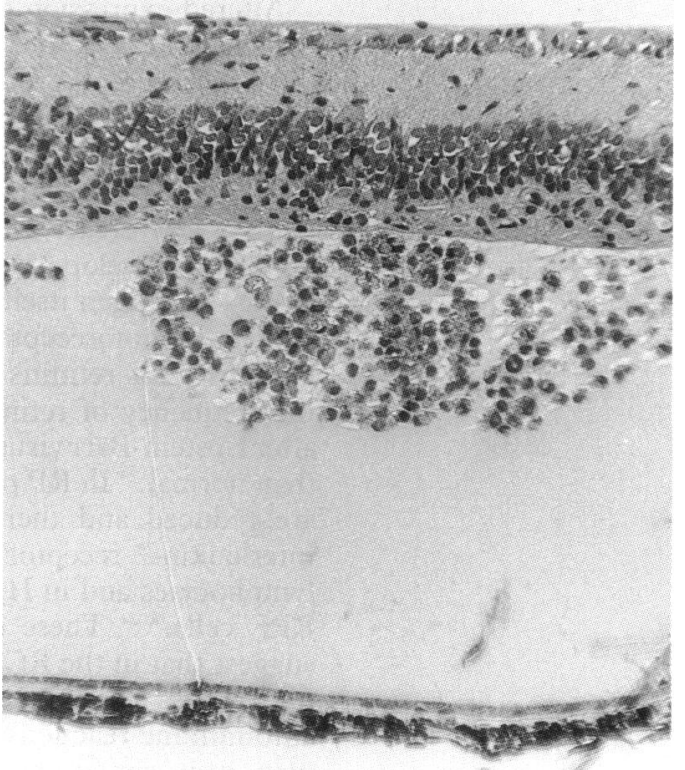

Fig $4 E$ 
debris accumulates between the photoreceptor layer and the RPE. Secondly, the interphotoreceptor matrix, which promotes retinal adhesion, is abnormal early in the course of the dystrophy. ${ }^{20}$ Thirdly, both the outer and inner blood-retinal barriers become spontaneously leaky to plasma protein as early as 21 days of age. ${ }^{21}$ In EAU these characteristics may allow the early accumulation of large amounts of subretinal fluid and subsequent detachment prior to the maximal influx of inflammatory cells, so enabling sufficient antibody to enter the subretinal space to produce a local Arthus reaction.

We did not find evidence of altered susceptibility to EAU with increasing age at sensitisation in the dystrophic rats though there was a tendency for EAU onset to be delayed in the older animals. There is known to be a reduced susceptibility to, and reduced severity of EAU in animals when photoreceptor outer segment turnover is reduced by disturbance of the normal day/night cycle. Thus, rearing in constant light ${ }^{3}$ (which induces photoreceptor degeneration) or constant dark ${ }^{22}$ (which moves Santigen to the inner portions of the photoreceptor layer) will reduce the severity of EAU as well as reduce the amount of S-antigen in the photoreceptor outer segments. We find that constant dark rearing also delays the onset of EAU even in the high responder Lewis strain of rat (E Kasp and S Suleyman, unpublished data). These findings contrast with the exacerbation of disease severity brought on by constant dark, in the collagen induced arthritis model of autoimmune disease. ${ }^{23}$

In the present experiments, where RCS photoreceptor metabolism is disturbed because of the RPE abnormality, it is difficult to know whether the amount of S-antigen available to sensitised recirculatory $T$ lymphocytes is reduced because of the reduced number of photoreceptors, or increased because of the disruption to the blood-retinal barrier. The tendency for an earlier onset, and shorter course of disease in the dystrophic strain, would be expected if there was a relatively greater access to a reduced amount of the target antigen.

Altered expression of EAU in the dystrophic strain might also arise from innate sensitisation to photoreceptor proteins, known to occur in both animals and humans with photoreceptor dystrophies. The RCS rat spontaneously develops IgM antibodies against photoreceptors in the early stages of dystrophy ${ }^{24}$ and a small minority develop raised levels of antibody against S-antigen itself. ${ }^{25}{ }^{26}$ Raised levels of antibodies to photoreceptors have been detected in humans with retinitis pigmentosa (RP) $)^{2728}$ and the frequency of retinal-specific B cells (found after Epstein-Barr virus transformation) is higher than normal. ${ }^{29}$ In RP patients $T$ suppressor cells are reduced and there are slight increases in interleukin-2 receptor expression or peripheral lymphocytes and in HLA class II expression on RPE cells. ${ }^{30-34}$ These changes, taken together, suggest that in the RCS rat as well as in retinitis pigmentosa the immune system is primed for autoimmune reactions against the retina, which may well contribute to the disease process. Antiretinal antibodies are also known to be associated with increased retinal vascular permeability in a variety of degenerative and inflammatory retinal disorders in man. ${ }^{35}$

In conclusion, this model of EAU demonstrates that a genetically determined biochemical dysfunction of target photoreceptor cells influences the clinical expression of retinal disease produced by peripheral autosensitisation to S-antigen. Further characterisation of the vascular and cellular events in early EAU in the RCS dystrophic rat may help to explain how these genetic factors could be operating at the molecular level.

This work was supported by grants from the Medical Research Council, the Iris Fund for Prevention of Blindness, the TFC Frost Charitable Foundation, the Frances and Augustus Newman Foundation, and the Trustees and Research (Endowments) Committee of St Thomas' Hospital. Dr E G Atkinson held anents) $C$ Edelsten holds an MRC Training Fellowship. We thank Dr Dewhirst and Mr D Lane for providing techn. We thank $\mathrm{Mr}$ ssistance with photography and histology.

1 Wacker WB, Lipton MM. The role of two retinal antigens in the production of EAU and its suppression by mycobacteria. Int Arch Allergy 1971; 41: 370-80.

2 Chan CC, Mochizuki M, Nussenblatt RB, Palestine AG McAllister G, Gery I, et al. T-lymphocyte subsets in EAU. Clin Immunol Immunopathol 1985; 35: 103-10.

3 Mirshahi M, de Kozak Y, Faure JP, Brisson JP, Falcon J Collin JP. Influence of light on $S$-antigen localization in rods and cones and immunopathogenicity in rats. In: Secchi AG. and cones and immunopathogenicity in rats. In: Secchi AG. pathology of the eye. Milan: Masson, 1989; 45-9.

pathology of the eye. Milan: Masson, $1989 ; 45-9$.
$4 \mathrm{Bok} \mathrm{D}$, Hall $\mathrm{O}$. The role of the pigment epithelium in the aetiology of inherited retinal dystrophy in the rat. $\mathcal{F}$ Cell Biol 1971; 49: 664-82.

5 Dowling J, Sidman RL. Inherited retinal dystrophy in the rat. f Cell Biol 1962; 14: 73-109.

6 Edwards RB, Szaimer RB. Defective phagocytosis in isolated rod outer segments by RCS rat pigment epithelium in culture. Science 1977; 197: 1001 .

7 Herron WL, Riegel BW, Myers OE, Rubinn ML. Retinal dystrophy in the rat. A pigment epithelial disease. Invest Ophthalmol 1969; 8: 595-604.

8 Mullen RJ, LaVail MM. Inherited retinal dystrophy: a primary defect in pigment epithelium determined with primary defect in pigment epithelium determined

9 LaVail MM, Sidman RL, Gerhardt CO. Congenic strains of 66: rats with inherited retinal dystrophy. $\mathcal{F}$ Heredity 1975

10 Atkinson EG, Dumonde DC. EAU in rats with spontaneous retinal dystrophy: susceptibility is dependent on the state of photoreceptor degeneration. Invest Ophthalmol Vis Sci 1989 30: (suppl): 81 .

11 Kasp E, Banga JP, Brown E, Wicking JM, Suleyman S, Elli $\mathrm{B}$, et al. An improved method for purification of S-antigen by hydrophobic chromatography on phenyl-sepharose $4 \mathrm{~B} . \mathcal{F}$ Immunol Methods 1987; 100: 147-52.

12 Stanford MR, Brown EC, Kasp E, Graham EM, Sanders MD Dumonde DC. Experimental posterior uveitis I: a clinical, angiographic and pathological study. Brf Ophthalmol 1987; 71: 585-592.

13 Brown EC, Kasp E, Dumonde DC. Morphometric analysis of T-lymphocyte compartmentation in experimental autoimmune uveoretinitis (EAU). Clin Exp Immunol 1989; 77: 422-7.

14 Faure JP. Autoimmunity and the retina. Curr Top Eye Res 1980; 2: 215-301.

15 de Kozak Y, Sainte-Laudy J, Benveniste J Faure JP. Evidence for immediate hypersensitivity phenomena in EAU. Eur $\mathcal{J}$ Immunol 1981; 11: 612-7.

16 de Kozak Y, Thillaye B, Renard G, Faure JP. Hyperacute form of EAU in Lewis rats; electron microscopic study. Graefes Arch Klin Exp Ophthalmol 1978; 208: 135-42.

17 Rao NA, Wacker WB, Marak GE. Experimental allergic uveitis. Clinicopathological features associated with varying doses of S-antigen. Arch Ophthalmol 1979; 97: 1954-8.

18 Stanford MR, Kasp E, Brown EC, Graham EM, Sanders MD Dumonde DC. Differential effect of Bordetella pertussis on experimental posterior uveitis in the black-hooded Lister rat. Arch Ophthalmol 1988; 106: 111-4.

19 Stanford MR, Robbins J. Experimental posterior uveitis. II. Electroretinographic studies. Brf Ophthalmol 1988; 72: 88-

20 LaVail MM, Pinto LH, Yasumura D. The interphotoreceptor matrix in rats with inherited retinal dystrophy. Inves matrix in rats with inherited retina
Ophthalmol Vis $S c i$ 1981;21:658-668.

21 Caldwell RB, McLaughlan BJ. Permeability of RPE cel junctions in the dystrophic rat retina. Exp Eye Res 1983; 36 : 415-427.

22 Tilgner S, Heidenreich A. Experimental allergische RetinoUveitis der Ratte: die Rolle des Neuroepithels. Ber. Dtsch. Ophthalmol Ges 1981; 78: 339-41. 
23 Hansson I, Holmdahl R, Mattsson R. Constant darkness

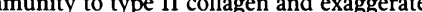
development of collagen-induced arthritis in DBA/l mice. $\mathcal{F}$ Neuroimmunol 1990; 27: 79-84.

24 Chant SM, Meyers-Elliot RH. Autoimmunity: a possible factor in the development of retinal degeneration in the RCS rat. Clin Immunol Immunopathol 1982; 22: 419-27.

25 Reid DM, Forrester JV, Campbell AM. Is there a humoral autoimmune response to retinal antigens in the RCS rat? Curr Eye Res 1987; 6: 561-8.

26 Brinckmann CJJ, Broekhuyse RM. Lack of immune response to retinal antigens in dystrophic rats. Ophthalmol Res 1981 ; 13; 188 .

Spalton DJ, Rahi AHS, Bird AC. Immunological studies in retinitis pigmentosa associated with retinal vascular leakage. $\mathrm{Br} \mathcal{F}$ Ophthalmol 1978

28 Chant SM, Heckenlively J, Meyers-Elliott RH. Autoimmunity in hereditary retinal degenerations. (1) Basic studies. Br f Ophthalmol 1985; 69: 19-2

EB-virus transformed human lymphocytes from uveitis and retinitis pigmentos patients secrete antibodies to retinal antigens. $\mathcal{J}$ Clin Lab Immunol 1988; 26: 107-11.
30 Detrick B, Newsome DA, Percopo CM, Hooks JJ. Class II antigen expression and gamma interferon modulation of monocytes and retinal pigment epithelial cells from patients with retinitis pigmentosa. Clin Immunol Immunopathol 1985; 36; 201-11.

31 Detrick B, Rodgrigues M, Chan C-C, Tso MOM, Hooks JJ. Expression of HLA-DR on retinal pigment epithelial cells in retinitis pigmentosa. Am 7 Ophthalmol 1986; 101: 584-90.

32 Heredia $\mathrm{CD}$, Vich JM, Huguet J, et al. Altered cellular immunity and suppressor cell activity in patients with primary retinitis pigmentosa. Br f Ophthalmol 1981; 65: $850-4$.

33 Hooks JJ, Detrick Hooks B, Geis S, et al. Retinitis pigmentosa associated with a defect in the production of interferon associated with a defect in the production
gamma. Am 7 Ophthalmol 1983; 96: 755-8.

34 Newsome DA, Quinn TC, Hess AD, Pitha-Rowe PM. Cellular immune status in retinitis pigmentosa. Ophthal-

35 Heckenlively JR, Solish AM, Chant SM, Meyers-Elliott RH. Autoimmunity in hereditary retinal degenerations. II. Clinical studies: antiretinal antibodies and fluorescein angiogram findings. Br f Ophthalmol 1985; 69: 758-64. 